\author{
Julie Smith', Toni Collier', Karen Dixon', Morenike Adebusuyi ${ }^{2}$,Tonye Sikabofori ${ }^{3}$, \\ Michaella Cameron-Taylor ${ }^{4}$,Toyin Baikie ${ }^{5}$, Cho Ee NG', Akintunde Akinkunmi', Suzanne \\ Guillum-Scott', Dot Moscrop' and Olufunso Adedeji' \\ 'University Hospital of North Durham, Durham, United Kingdom; ${ }^{2}$ Chelsea and Westminster Hospital, London, \\ United Kingdom; ' ${ }^{B}$ irmingham Community Health Care, Birmingham, United Kingdom; "Whipps Cross Hospital, \\ London, United Kingdom; ${ }^{5}$ Hook Surgery, Merritt Medical Centre, Kingston upon Thames, United Kingdom; ${ }^{6}$ LP \\ Consulting Ltd., London, United Kingdom
}

$\mathrm{T}$ he severe acute respiratory syndrome coronavirus 2 (SARS-CoV-2) or COVID-19 defined our world in 2020. In over a year since the World Health Organization (WHO) declared the COVID-19 outbreak a pandemic, on 11th March 2020, over 130 million people have contracted the virus worldwide, of whom 2.9 million have died. Healthcare systems have weathered unprecedented stresses, but the modern medical and technological advances have come up with vaccines within a year of the WHO declaration. Consequently, as healthcare workers look forward to more normal and less stressful times, some United Kingdom National Health Service (NHS) colleagues have had a retrospective look at their experiences at the beginning of the pandemic.

\section{Fear and anxiety}

Fear and anxiety is the best way to describe my initial feelings at the start of the COVID pandemic. I can remember thinking surely it cannot be as bad as they were saying. How wrong I was!

Being told we had to attend 'urgent' training in preparation for our redeployment to the wards. Not only feeling worried about working on a ward, having not worked on a ward for over 10 years, but listening to the daily government briefing of how many health professionals were dying or critically ill was so frightening. I often cried listening to the news. It was a real rollercoaster of emotions! We are all health professionals wanting to help in this crisis and 'do our bit', but it honestly felt like we were being sent into a battle we were not going to win. I was scared. The media did not help. I was anxious coming home from shift, too anxious to cuddle my little girl. It was a very stressful time for us all.

The hospital atmosphere was different; walking through the corridors, personally I felt there was a genuine concern for each other. Passing NHS colleagues in the corridor, exchanging a reassuring smile or even just a 'are you okay?' meant so much. I kept in contact with my close friends who had been redeployed to the COVID wards, checking they were okay and supporting them as much as possible. It really is good to talk!

Trying to reassure our patients as they too were frightened, no visitors allowed, staff covered in personal protection equipment! But everyone coming together trying to keep the spirits high. I can honestly say I do feel proud to work for the NHS!

Julie Smith

Colorectal Nurse Specialist

Adrenaline and panic

Working in theatres, soon to be intensive care unit (ICU) overspill. Scare tactics used by the government and the media. Learning about the disease and how to manage it from other countries. Consultant anaesthetists leading training for operating department practitioners (ODPs) and theatre nurses about what we were soon to face. It was predicted it will hit our region within 2 weeks. We now know from them what is expected, I am prepared.

Days go by, and the patients start to come in, the beds are filling. The patients start to reach ICU. You have no real idea what you are about to face and no clue as to how many will be admitted. All you currently know is there are not enough ventilators if our highest hospital tier system is reached. The country goes into national lockdown, all anyone is talking about is the pandemic and the death rate as it continued to rise.

At home I had an underlying adrenaline that kept me going throughout the day. Then one day, I realised I had no taste, no smell, and I had a persistent, piercing headache. The headache did not go away no matter how many four hourly paracetamol that I took. At the time, these symptoms were not recognised, and occupational health said they could only test for core symptoms which were a high temperature and a new persistent cough. I texted all the current and previous surgical registrars I had worked 
with, and they all individually agreed it sounded like COVID. I laid there in an absolute panic of where this was going, how bad was it going to get, how quickly would my symptoms progress.... and no one knew.

Toni Collier

Colorectal Surgical Practitioner

\section{Fear and uncertainty}

COVID 19 - to me this meant fear and uncertainty. Not fear of contracting the disease, I did, and I was relatively well with it. It was fear of the unknown.

I was redeployed to a ward, and this caused fear and uncertainty. As I have not worked on a ward for over 20 years, it felt very alien to me. I was not familiar with the new electronic systems of recording and monitoring. There was a chart for everything, and there were a lot of boxes to tick. There were lots of processes and protocols to follow. Whilst I felt my clinical knowledge was acceptable, I felt out of my depth and, as a senior nurse, I felt very unsure and unconfident. I did not like the feelings and emotions the move created, and it upset me that I felt like this. I love my job as a nurse and love my current role - yet I did not enjoy the very essence of what I felt made me a nurse. I managed, I survived, but I did not enjoy it.

If I had to identify a positive from the situation, it would be the establishment of new relationships, both within the ward setting and with other redeployed nurses like myself. However, as we are in a new wave of this pandemic, and with a new mutated variant I am dreading being redeployed again - it will come, I am not naïve to think it wouldn't, but I am not looking forward to the challenge.

Karen Dixon

Colorectal Nurse Specialist

\section{Staying home}

Halfway through the 90-min drive back home from work on 24th March 2020, I suddenly became quite feverish and had rigours which lasted about $10-15 \mathrm{~min}$ and then resolved. However, on getting home about 40 min later, the fever started again. This was the beginning of a 23-day battle with COVID-19. I immediately isolated at home but, despite severe generalised muscle pain, headache, fever, pouring out of sweat, and loss of smell and taste, I remained in a state of total denial until the middle of the second week of illness when I started to have some degree of difficulty with breathing.

Although I seemed to be breathing ok, I knew I was not moving air as my lungs felt like they were filled with plastic. I remained at home, checking oxygen saturations on my phone app, and continued self-treatment symptomatically, whilst also maintaining a positive outlook by holding strong to my faith in God to keep my hope alive. Staying at home seemed like the most sensible option. The advice at the initial stage was to stay at home unless one faces severe breathing difficulties. Moreover, somehow, I did not think ventilation would help, so I had made up my mind that I would not be ventilated if I could help it.

Time lost all meaning, but towards the middle of the third week I began to slowly recover physically. The associated fatigue and anxiety that followed has however taken several more months to resolve. COVID is real, it is serious, and it is still lurking out there. My advice? Continue strict handwashing and sanitizing, keep socially distanced at all times, and please, please keep wearing your facemasks, and get vaccinated.

\section{Morenike Adebusuyi Consultant Paediatrician}

\section{Emotional and physical need}

COVID-19 was an affliction I bore in March 2020. I was ill at home for 10 days before being admitted with the second ambulance that was called to my home. COVID-19 was the confirmed diagnosis on arrival at hospital and over the first day I was admitted to a medical ward for isolated management of symptoms. No family could visit, no phone calls, etc. It was a very worrying time.

A day after being admitted my health deteriorated significantly. I was admitted to the intensive care unit. At this time, they had shared with my wife - via phone calls - that they did not think I was going to make it through the night. COVID was a threat to my life in real time and real terms. This was the narrative that was shared with my wife, at home with our children, for 2 days. I was placed on high flow oxygen apparatus. I was bedridden; I could not talk and could not sleep due to the machinery. It was a very frightening experience. Over 5 days my treatment included that for COVID pneumonia. I was barely alive.

On the sixth day in intensive care, my wife managed to video call me. This was the change that led to my journey of recovery. It was emotional for both of us. My body responded to the emotional and physical need of being back with my family. It was after this call that my health began to improve to the point where I was discharged from hospital 4 days later. Post-COVID treatment included physiotherapy for breathing, walking and managing food. It was a frightening experience, which meant that I was away from my work for 3 months of recovery. Long COVID symptoms are still present, however I am now back at work.

Tonye Sikabofori

Consultant Psychiatrist \& Divisional Medical Director 
Almost...,

'Are you happy to be called in if the situation turns for the worst?'

'Yes'

The COVID pandemic almost stole my father away from me. I still reflect on how his 'mild' symptoms of anorexia, lethargy and low-grade temperatures quickly transformed into disorientation, swinging pyrexia and urinary incontinence. Being the medic in the family was a blessing but also a curse as I understood all too clearly the gravity of the situation when my father was admitted into hospital in April 2020. My mother had recently recovered from COVID-19 after 10 days of mild flu-like symptoms.

When I answered 'yes' to the question, my father had been in multiorgan failure. The intensive care consultant described this new virus as an 'assassin' which was wreaking havoc on almost every major organ in my father's body. He was intubated on day 10 after failing a trial of continuous positive airway ventilation. He was on renal dialysis from day 15 due to refractory hyperkalaemia. I had to translate these to my family as 'he is not doing very well', and informed them that if his heart stopped, it will not be restarted.

Against all odds, this 65-year-old type 2 diabetic began to respond slowly but enough to allow a tracheostomy insertion and then eventual decannulation. After 6 weeks, he was discharged home, a shadow of his former self, but with love and attention, he continues to make strides in his health.

This experience has been life changing for my father and for us, his family. The determined highly skilled medical team saved my father's life and I worked fiercely as his advocate to ensure they did not give up on him. As a clinician, I remain in awe of how our decision has such far-reaching ripples of effect on not just the patient, but the wider family.

Michaella Cameron-Taylor Specialist Trainee in Ear, Nose and Throat Surgery

\section{Hectic year}

It has been a hectic year that is for sure. I still have the first Public Health England missives warning us to look out for signs of SARS-Cov-2 in travellers returning from Wuhan, China, then other parts of Asia, and then Lombardy in Italy. It did not seem to apply to us, but within weeks, we were shutting surgery doors, applying technology to consult at a safe distance and reading ever-changing guidelines. Then there was the scramble for non-existent, or low-quality PPEs, and no tests were available except in hospitals.

On a personal note, I wore face mask, followed handwash, maintained safe distance and viewed everyone with suspicion. And while I was still working, I tried to safeguard my family members who were on the shielded patients list. At one time, I desperately sought a test for my symptomatic husband. I discovered scenic places to walk in the area where I had lived for ages.

Politically, it was constant doublespeak. In April 2020, the Secretary of State for Health and Social Care, at a Downing Street press briefing, said the scientific case for wearing masks was weak (help!!!). At the time, Scotland, and many European countries had already advised their citizens to wear masks. Then there was the daily toll of the dead, or admission into hospitals.

Never will I forget the sound of my first positive COVID patient, an asthmatic, single mum, struggling to breathe over the phone.... that gut wrenching feeling of fear and despair.... and the sheer relief when she made it out of hospital. The double-edged sword of patients grateful they could still speak to a doctor albeit via phone or video, and the uneasy feeling and disquiet that comes with practising in unusual circumstances.

It is a matter of time, we MUST and WILL win the war against COVID.

Toyin Baike

General Practitioner

\section{Untimely relocation}

As a ST5 in General Surgery from Mersey deanery, I started my time out of training for research in February 2020 , only to be met with the start of the pandemic within weeks. At the start of the pandemic, I had just relocated to Newcastle with plans to start a research job for a $\mathrm{PhD}$ with funding. This came to an abrupt end and, due to social restriction, I was unable to return back to my training job in Mersey Side. Consequently, I lost funding for the research project, and I was left in turmoil.

During this time, I was able to temporarily take up a clinical job while using this time to work with the research team to come up with a new proposal and explore new funding stream for it. I worked to support the local research team in setting up COVID-related research project. Finally, after 6 months a new proposal had been written and I managed to register myself to start the PhD as initially planned.

This experience has been one of facing setbacks and being resourceful to overcome challenges. Fortunately, my training programme director was supportive and reassured me that once social restrictions were lifted, I could come back into training. She however continued to support my desire to do research and was in favour of extending my time out of training should this be required.

Cho Ee NG

Specialist Trainee - General Surgery 


\section{Unintended consequences}

At the beginning of the UK national shutdown in March 2020, the First Tier Tribunal (Health, Education and Social Care Chapter) of Her Majesty's Courts and Tribunals Service (HMCTS) transitioned from holding in-person hearings of patients' appeals against detention under the Mental Health Act 1983 to, initially, telephone and then, subsequently, video hearings. This was driven by an understandable wish to not have delays in hearings that might lead to patients being detained for longer than necessary; the video hearings in particular were regarded as being better for involving patients as fully as possible in the unusual circumstances.

What, perhaps, had not been fully taken into consideration were some hallucinatory symptoms so often displayed by patients whose appeals were being heard: that, for example, people on the television were talking about them, or that familiar faces that had not been seen for some time had fallen prey to the nefarious conspiracies of abductors holding them captive inside computers. As a member of the aforesaid Tribunal (and therefore sitting in a Judicial as opposed to a Clinical capacity), the author is aware of a number of hearings which appeared to reinforce some of the illness-driven hallucinatory beliefs of patients, and these would probably not have strengthened the patient's case against their detention. It is clear to me that HMCTS adapted admirably to the realities of the COVID era; perhaps, with time, so will the rest of us.

Akintunde Akinkunmi Consultant Forensic Psychiatrist

\section{New lifestyle}

On 30th March 2020, the second week of the first national lockdown, I delayed my return from annual leave by 1 day, as I was uncertain what changes had occurred in the first week of the lockdown. Communication was slow about requirements, needs and fears. On 9th April, a medical secretary tested positive for COVID-19. As a response, a rota was devised so secretaries came in on different days, but this was soon abandoned to cope with administrative work. At the time, social distancing and hygiene standards in limited space and shared facilities were bespoke. Fortunately, I work with consultant surgeons, and their expertise and measures put in place, gave some guidance on how to behave.

I was gripped by a television programme, 'The Italian COVID-19 hospital where no medics had been infected'. Armed guards patrolled all the corridors with walk-in disinfection machines that looked like airport scanners. The nightmare of coronavirus disease became apparent. This documentary showed the true scale of barrier nursing at its finest and how deadly a disease this was if not treated and handled correctly. I immediately put my own measures in place both in my private and professional life to remain vigilant.

My life has changed forever; I have never wanted to put myself in a lockdown situation as much as I have the last year. I know that even going forward, this is the new lifestyle I will adopt for myself. My prayer is that the vaccine is going to deliver and save lives in the future.

Suzanne Guilliam-Scott Medical Secretary

\section{Sacrifice}

When the COVID pandemic began, I remember thinking this is never going to be as bad as China. However, when the stories and the news report came in from Italy's intensive care units, the feeling of trepidation and disbelief was almost overwhelming.

I was in a risk group with a heart condition and obesity. My children were very concerned but it was my husband's reaction which was the hardest to bare. We have been married for 35 years, and we have four grown-up children and grandchildren. He begged me not to go to work, to report sick, or to leave the profession altogether. I played down my own worries and tried my best to reassure him and the family that I was going to be fine.

I went to work initially isolating from my family, but my husband, after 2 weeks, stated he could not stand being alone and worrying about me. So, I moved home and over time he accepted that this was a job that had to be done. He clapped with gusto every Thursday, and I was embarrassed. My daughters often said that they are proud of me, again embarrassing. It is my job and I have, like many thousands of other frontline workers, just got on with it.

Dot Moscrop

Nurse Practitioner Clinical Decisions Unit

(After getting the first dose of her vaccination in February 2021, both Dot and her husband got infected with COVID-19. While Dot was fine, her husband spent 3 weeks in hospital, including 5 days on the intensive care unit. Dot is back at work, and her husband is making good recovery - OA).

And work continued....,

On the eve of the March 2020 lockdown, as I left my office, the air of uncertainty and anxiety that had been palpable all week hung on the walls of the deserted and silent offices. I hoped everybody would be back safe when life returned to normal. When I got home that 
night, I wrote my will, and I then put COVID-19 into a 'what will be will be' compartment in my brain, and got on with life.

Almost everybody was affected one way or another, but work went on. From the catering assistant who spoke lovingly of her grandfather who had been admitted to a COVID ward, but whom she could not see, to the auxiliary nurse whose daughter was having a baby almost directly above where she worked, one floor up, but was uncertain when she would see her grandchild.

On my first week of on-call during the lockdown, a man in his mid-70s was admitted with abdominal pain. However, it soon became clear that it was his chest that was the source of his rapid decline from a severe illness. Despite joint management with the acute medical team and intensivists, his deterioration continued. At our umpteenth multidisciplinary team discussion about his outlook, reviewing all his investigations and treatment thus far, it was decided that, in view of his rapid and continued deterioration despite optimal care, his outlook was terminal, and he was put on an end-of-life pathway.

Immediately after this decision, a Nursing Sister, seconded to the ward, completed her drug round and came over. She asked if she could sit with the patient, and whispered softly, 'that's the grandfather of my three children'. He died $2 \mathrm{~h}$ later, just over $12 \mathrm{~h}$ after admission, of COVID-19-related lung complications according to the coroner's report.

Olufunso Adedeji

Consultant Colorectal Surgeon

\section{Conclusion}

The psychological sequelae of the COVID-19 pandemic on healthcare workers are emerging, but the long-term effects are yet to be seen [1]. By September 2020, Amnesty International estimated that over 7,000 health workers had lost their lives to COVID-19 around the world [2].

\section{References}

1. Mehta S, Machado F, Kwizera A, Papazian L, Moss M, Azoulay É, et al. COVID-19: a heavy toll on health-care workers. Lancet Respir Med 2021; 9(3): 226-8. doi: 10.1016/ S2213-2600(21)00068-0

2. Amnesty International. More than 7,000 health worker deaths from COVID-19 globally - UK deaths third-highest. 2020. Available from: https://www.amnesty.org.uk/press-releases/more7000-health-worker-deaths-covid-19-globally-uk-deaths-thirdhighest [cited 11 April 2021]. 